\title{
Modified Octagonal Photonic Crystal Fiber for Residual Dispersion Compensation over Telecommunication Bands
}

\author{
Redwan AHMAD ${ }^{1}$, Matej KOMANEC ${ }^{2}$, Dmytro SUSLOV ${ }^{2}$, Stanislav ZVANOVEC ${ }^{2}$ \\ ${ }^{1}$ Dept. of Electrical and Electronic Engineering, World University of Bangladesh, Dhaka, Bangladesh \\ ${ }^{2}$ Dept. of Electromagnetic Field, Czech Technical University in Prague, Czech Republic
}

redwan.ahmad@eee.wub.edu.bd, komanmat@fel.cvut.cz, suslodmy@fel.cvut.cz, xzvanove@fel.cvut.cz

Submitted October 14, 2017 / Accepted February 1, 2018

\begin{abstract}
A modified octagonal photonic crystal fiber (MO-PCF) is proposed and numerically investigated for the purpose of residual dispersion compensation in the optical transmission link. The results show that the proposed fiber with optimized parameters exhibits ultraflattened negative dispersion over the $300 \mathrm{~nm}$ band $(1380 \mathrm{~nm}$ to $1680 \mathrm{~nm})$ with an average dispersion of $-506 \mathrm{ps} /(\mathrm{nm} \cdot \mathrm{km})$ and an absolute dispersion variation of $11.3 \mathrm{ps} /(\mathrm{nm} \cdot \mathrm{km})$. In addition to large negative dispersion, the proposed $M O-P C F$ also exhibits high birefringence in the order of 0.0207 at the $1550 \mathrm{~nm}$ wavelength. The proposed MO-PCF can be advantageously used especially for residual chromatic dispersion compensation in the wavelength-division-multiplexing optical fiber transmission system. The proposed fiber design is easy to draw and is tolerant to manufacturing imperfections.
\end{abstract}

\section{Keywords}

Finite element method, negative flat dispersion, residual dispersion compensation, high birefringence, photonic crystal fiber.

\section{Introduction}

In optical fiber transmission systems, chromatic dispersion in a single mode fiber (SMF) is challenging as it causes broadening of the optical pulse and limits the link bandwidth especially for higher data rates. Typical standard single-mode fiber has positive dispersion in the range of $\sim 10$ to $20 \mathrm{ps} /(\mathrm{nm} \cdot \mathrm{km})$, therefore dispersion compensating fibers (DCFs) are extensively used to compensate for the chromatic dispersion [1]. However, some flattened positive dispersion still remains even after dispersion compensation, which could result in serious restrictions in the transmission data rates [2]. Hence, a fiber having flattened negative dispersion becomes an essential component of optical communication systems. Moreover, dispersion compensation over a wide wavelength range is particularly required for wavelength division multiplexing (WDM) [3] over the entire range $1260 \mathrm{~nm}-1675 \mathrm{~nm}$ of the telecom- munication bands. On the other hand, to minimize losses and reduce costs, the inserted residual dispersion compensating fiber (R-DCF) should be as short as possible with high negative dispersion and flattened characteristics to compensate for dispersion in wavelength-division-multiplexing systems effectively [4], [5].

Photonic crystal fibers (PCFs) with high negative and flattened dispersion characteristics have been proposed by several groups studying residual dispersion [6-10], [18], [20], [21], [24]. Franco et al. [6] proposed a PCF with seven defected air-holes in the core region and having a low average negative dispersion of $-179 \mathrm{ps} /(\mathrm{nm} \cdot \mathrm{km})$ over the $\mathrm{S}+\mathrm{C}+\mathrm{L}+\mathrm{U}$ wavelength bands. Another PCF has been proposed in [7] based on a genetic algorithm with resulting average negative dispersion of $-212 \mathrm{ps} /(\mathrm{nm} \cdot \mathrm{km})$ and an absolute dispersion variation of $11 \mathrm{ps} /(\mathrm{nm} \cdot \mathrm{km})$ over the $\mathrm{S}+\mathrm{C}+\mathrm{L}+\mathrm{U}$ wavelength bands. By having low average dispersion, the PCFs mentioned above require a long length to compensate a standard SMF-based link. One of the main disadvantages lies in the core doping as presented in [7] when describing, in particular, fabrication difficulties. An equiangular spiral PCF (ES-PCF) proposed by Islam et al. in [8] had an average negative dispersion of $-227 \mathrm{ps} /(\mathrm{nm} \cdot \mathrm{km})$ along with high birefringence. Though this design exhibited high negative dispersion, in addition to promising polarization-maintaining characteristics, the main drawback was introduced by the elliptical air hole in the center core which made the whole design and future fabrication processes more complex. More recently PCF in PCF design has been proposed by [9] which showed an extremely high negative dispersion of $-457.4 \mathrm{ps} /(\mathrm{nm} \cdot \mathrm{km})$ over the $\mathrm{E}+\mathrm{S}+\mathrm{C}+\mathrm{L}+\mathrm{U}$ wavelength bands. However, small air holes in the inner PCF structure make the complex design extremely difficult to fabricate, as was as well mentioned in [9]. In previous work [10], Samiul et al. proposed MO-PCF with a specific core region shape exhibiting a negative dispersion of $-465.5 \mathrm{ps} /(\mathrm{nm} \cdot \mathrm{km})$ with an absolute dispersion variation of $10.5 \mathrm{ps} /(\mathrm{nm} \cdot \mathrm{km})$ covering a $215 \mathrm{~nm}$ flat band. In the same year, Hasan et al. [18] published a similar design as in [10], where they achieved flatness over $240 \mathrm{~nm}$ band with higher negative dispersion value compared to [10]. A pentagonal PCF design has been proposed by Xuyou et al. [21] where they achieved $250 \mathrm{~nm}$ 
flatness with an average negative dispersion of $-474 \mathrm{ps} /(\mathrm{nm} \cdot \mathrm{km})$ and birefringence in the order of $1.75 \times 10^{-2}$. On the other hand, MO-PCF has been proposed by Shubi, F. et al. [20] where they reported only $95 \mathrm{~nm}$ flatness with negative dispersion value from $-226 \mathrm{ps} /(\mathrm{nm} \cdot \mathrm{km})$ to $-290 \mathrm{ps} /(\mathrm{nm} \cdot \mathrm{km})$. A square photonic crystal fiber has been proposed by Mahmud et al. [24], where they achieved flatness over only $170 \mathrm{~nm}$ using silica PCF and $230 \mathrm{~nm}$ using lead-silicate PCF. However, compared to silica PCF, the fabrication cost is much higher in the case of lead-silicate PCF as a dispersion compensating fiber.

Our main research goal was to propose a new improved design of a photonic crystal fiber which can cover wider wavelength band (flattened) while also providing high negative dispersion value. This was achieved by inserting an extra elliptical ring in the PCF core region, which in turns also gave a higher negative dispersion value while also providing wider wavelength band compared to above- mentioned results.

In this paper, we propose a new design based on a modified octagonal photonic crystal fiber acting as R-DCF with a double row elliptical shape core region that ensures higher average negative dispersion with flattened characteristics, ultra-high birefringence and low confinement loss. The paper presents a considerable extension of our previous work presented in [10]. The newly proposed MO-PCF exhibits negative dispersion of $-506 \mathrm{ps} /(\mathrm{nm} \cdot \mathrm{km})$ covering a $300 \mathrm{~nm}$ flat band (from $1380 \mathrm{~nm}$ to $1680 \mathrm{~nm}$ ) with negative dispersion $-511 \mathrm{ps} /(\mathrm{nm} \cdot \mathrm{km})$ at wavelength $1550 \mathrm{~nm}$. Thanks to having a modest number of design parameters, it makes the design significantly less complex compared to other approaches [7-9] and therefore, our $\mathrm{MO}-\mathrm{PCF}$ is considerably easier to fabricate.

\section{Structure Design of the Proposed MO-PCF}

Figure 1 shows the proposed MO-PCF with optimized air-hole diameters $d$ and $d_{1}$. We have selected an octagonal structure for R-DCF, as this structure offers smaller confinement losses along with better dispersion accuracy [10-12]. The spacing between the air-hole centers is indicated as $\Lambda$, whereas $\Lambda_{1}$ depicts the spacing between air-hole centers on the same ring. Octagonal structure $\Lambda_{1}$ is related to $\Lambda$ by the relation $\Lambda_{1}=0.765 \Lambda$. By replacing the first ring of air holes with an elliptical core shape (see in Fig. 1(a) within the full structure and in Fig. 1(b) inner elliptical ring), birefringence increases and negative dispersion characteristics are flattened. Moreover, we designed two air holes in the first ring with a diameter equal in size to the air holes in the outer ring to increase the range of flatness [10]. Two air hole elliptical rings in our new design with ten extra air holes result in a new structure design that leads, in turn, to the broadening of the flatness band of the proposed R-DCF.
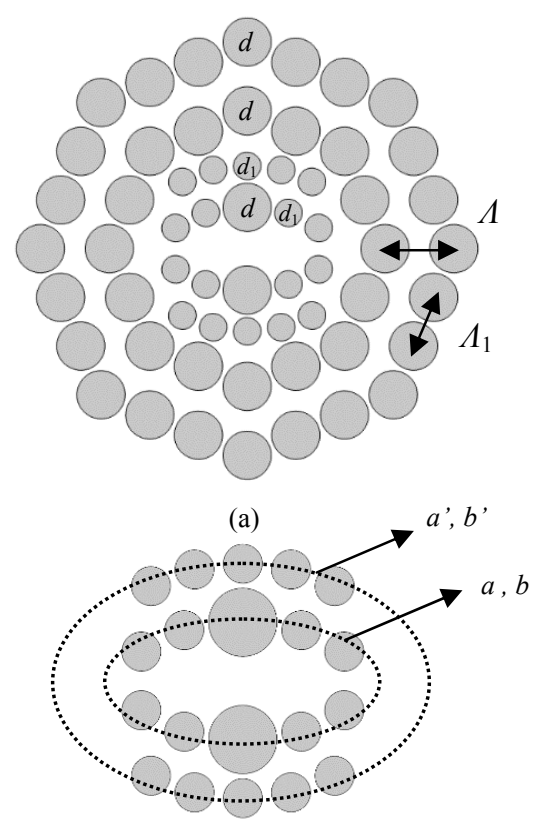

(b)

Fig 1. (a) Cross section of 3 ring MO-PCF. (b) Elliptical core shape (where $a, b$ and $a^{\prime}, b^{\prime}$ denote the lengths of the major and minor axes of the $1^{\text {st }}$ and the $2^{\text {nd }}$ ring).

The lengths of the major and minor axes of the elliptical shapes of the $1^{\text {st }}$ and $2^{\text {nd }}$ rings were denoted as $a, b, a$, and $b$ ' respectively (see Fig. $1 \mathrm{~b}$ ). The optimum values of $a, b, a^{\prime}$ and $b^{\prime}$ are $1.2 \mu \mathrm{m}, 0.6 \mu \mathrm{m}, 1.6 \mu \mathrm{m}$ and $1.2 \mu \mathrm{m}$, respectively. By using only two optimized diameters $d$ and $d_{1}$, the proposed R-DCF is formed.

\section{Simulation Results and Discussion}

To optimize the proposed structure, we have used COMSOL multiphysics software featuring the full-vector finite element method (FEM) with a perfectly matched boundary layer (PML). The material dispersion obtained from the three-term Sellmeier formula is directly included in the calculation. The dispersion, confinement loss and effective area of the proposed MO-PCF are evaluated based on the following equations [13]:

$$
\begin{gathered}
D(\lambda)=-\lambda / c\left(d^{2} \operatorname{Re}\left[n_{\mathrm{eff}}\right] / d \lambda^{2}\right) \mathrm{ps} /(\mathrm{nm} \cdot \mathrm{km}), \\
L_{\mathrm{c}}=8.686 \times k_{0} \operatorname{Im}\left[n_{\mathrm{eff}}\right] \times 10^{3} \mathrm{~dB} / \mathrm{km}, \\
A_{\mathrm{eff}}=\left(\iint|E|^{2} \mathrm{~d} x \mathrm{~d} y\right)^{2} /\left(\iint|E|^{4} \mathrm{~d} x \mathrm{~d} y\right) \mu \mathrm{m}^{2}
\end{gathered}
$$

where $\operatorname{Re}\left[n_{\text {eff }}\right]$ and $\operatorname{Im}\left[n_{\text {eff }}\right]$ are the real and imaginary parts of the effective refractive index, $c$ is the velocity of light, $k_{0}$ $=2 \pi / \lambda$ free-space wave number in vacuum and $E$ is the electric field intensity derived by solving the Maxwell equations. Polarization-maintaining (PM) fibers have highly asymmetrical core region, which in turn provide an extremely high effective index difference between the two orthogonal polarization modes. The modes of a perfect six-fold symmetric core and cladding structure are not birefringent [23]. In practice, however, the large glass-air index 
difference means that even slight asymmetry in the structure yields a degree of birefringence. The propagating mode is then split into two co-propagating polarization orthogonal modes. Birefringence is the difference between the mode indices of material/structure for two orthogonal polarization fundamental modes.

$$
B=\left|n_{\mathrm{x}}-n_{\mathrm{y}}\right|
$$

where $n_{\mathrm{x}}$ and $n_{\mathrm{y}}$ are the effective refractive indices of $x$ and $y$ polarization state respectively. In high bit-rate fiber transmission systems, PM fiber plays an important role. Such as PM fibers can eliminate the influence of polarization mode dispersion (PMD) or stabilize the operation of optical devices [19]. The numerical results are reported for an optimized structure with the number of rings $N_{\mathrm{r}}=5, d / \Lambda=0.7$, $d_{1} / \Lambda=0.4$ and $\Lambda=1 \mu \mathrm{m}$ for R-DCF. Typically, for better compensation, an R-DCF should have flattened negative dispersion with significantly high magnitude across the whole bands of the wavelength of interest. The proposed and optimized design exhibits an average value of chromatic dispersion equal to $-506 \mathrm{ps} /(\mathrm{nm} \cdot \mathrm{km})$ with a dispersion variation of $11.3 \mathrm{ps} /(\mathrm{nm} \cdot \mathrm{km})$ between $-500.5 \mathrm{ps} /(\mathrm{nm} \cdot \mathrm{km})$ and $-511.8 \mathrm{ps} /(\mathrm{nm} \cdot \mathrm{km})$ in the wavelength range $1380 \mathrm{~nm}$ to $1680 \mathrm{~nm}$ for the fundamental slow axis mode - see Fig. 2.

As the effective refractive index of the $y$-axis mode is higher than the $x$-axis, the $y$-polarization mode acts in slow-axis mode and the $x$-polarization mode acts as the fast-axis mode. Meanwhile confinement loss represents one of the most important issues when designing the R-DCF, though such losses can be minimized by inserting extra rings of air holes surrounding the core of the MOPCF without affecting the characteristics of the dispersion curve [14]. Figure 3 presents confinement loss values for the R-DCF designed for the test case with four to ten rings of air holes surrounding the core. It can be clearly demonstrated, that confinement loss at $1550 \mathrm{~nm}$ reaches $5 \mathrm{~dB} / \mathrm{km}$, $0.46 \mathrm{~dB} / \mathrm{km}$ and $0.045 \mathrm{~dB} / \mathrm{km}$ when $N_{\mathrm{r}}$ (number of rings) is 8,9 and 10 respectively.

Uncertainties, which can be experienced during fiber fabrication, need to be considered, where a $1 \%$ variation of

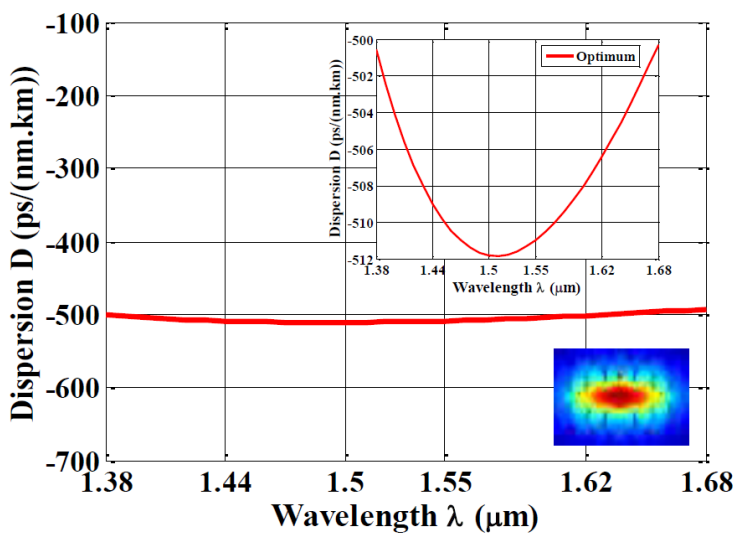

Fig. 2. Chromatic dispersion as a function of wavelength with field distribution (for number of rings $N_{\mathrm{r}}=5$ ); inset shows electric field distribution for slow axis mode $(y$ polarization).

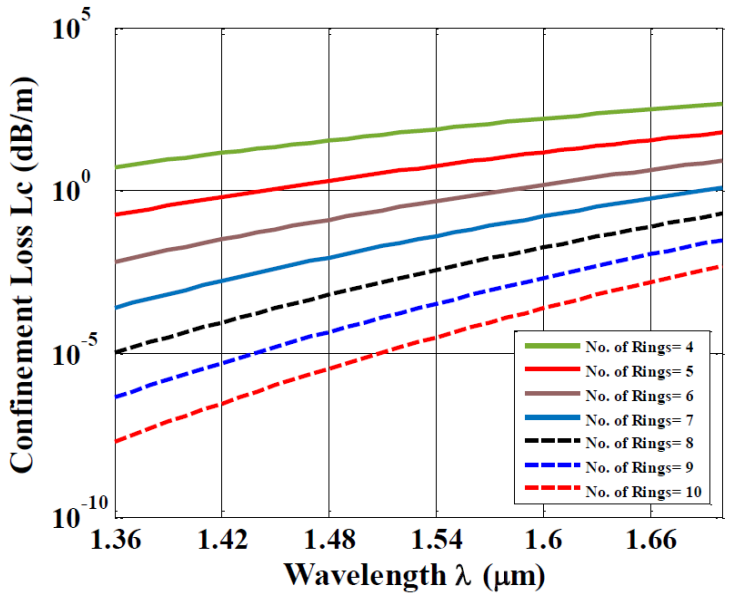

Fig. 3. Confinement loss as a function of wavelength for a different number of rings.

structural parameters is typically acquired while the fiber is being drawn [15]. For that reason, when numerically analyzing proposed fiber performance, we have included the influence of fabrication by up to a $2 \%$ variation uncertainty in global diameters of the proposed MO-PCF. Results including uncertainties of particular parameters are plotted in Fig. 4 to 6 (all for the case of $N_{\mathrm{r}}=5$ ). From the tolerance analysis, it can be seen that $+2 \%$ variation in $d_{1}$ has a mea-

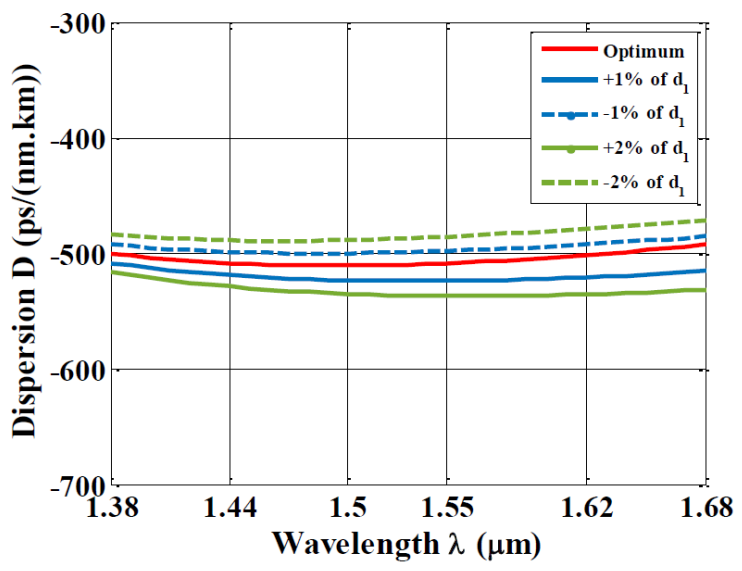

Fig. 4. Dispersion as a function of wavelength for variation of $d_{1}$ from $\pm 1 \%$ to $\pm 2 \%$.

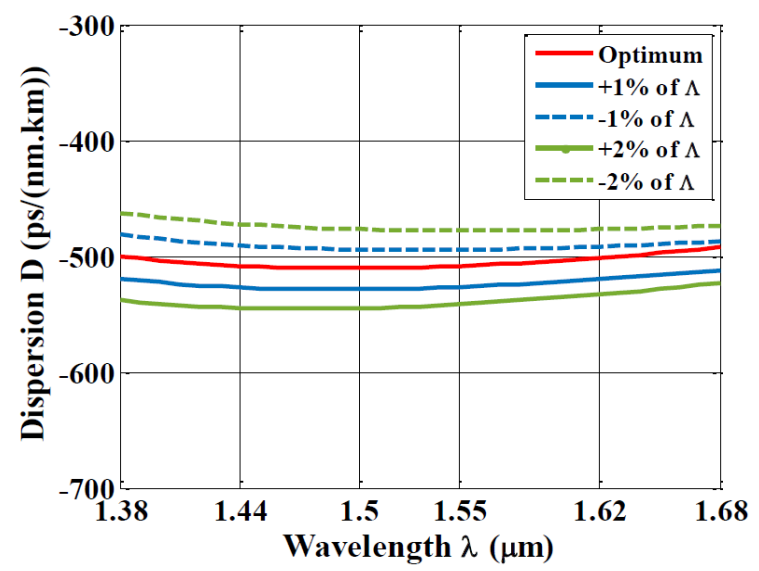

Fig. 5. Dispersion as a function of wavelength for variation of pitch (A) from $\pm 1 \%$ to $\pm 2 \%$. 
ger effect in the dispersion curve flatness, but increases the average chromatic dispersion up to $+4 \%$ from the optimum value (when almost all fiber parameters such as dispersion, birefringence and flatness are met). Moreover, for the purpose of the sensitivity of final design parameters during fabrication, we have also performed a tolerance analysis of pitch (A) variation which is plotted in Fig. 5. From the figure it can be determined that for the variations of pitch of $+1 \%,+2 \%,-1 \%$ and $-2 \%$, the average dispersion becomes $-524 \mathrm{ps} /(\mathrm{nm} \cdot \mathrm{km}),-542 \mathrm{ps} /(\mathrm{nm} \cdot \mathrm{km})$, $-488 \mathrm{ps} /(\mathrm{nm} \cdot \mathrm{km})$ and $-470 \mathrm{ps} /(\mathrm{nm} \cdot \mathrm{km})$, respectively, with flattened characteristics. Afterwards, we set the tolerance analysis of the major and minor axes of the central core shape. It is evident that changes in parameters $a, b, a$ ' and $b$ ' of up to a $2 \%$ variation increase the average dispersion towards $-557 \mathrm{ps} /(\mathrm{nm} \cdot \mathrm{km})$ without affecting the flattening of characteristics (Fig. 6). With the exception of the results mentioned above, where we analyzed the MO-PCF by using ring number $N_{\mathrm{r}}=5$ for the optimum condition, we have demonstrated the effect on dispersion flatness by changing the ring number (see the influence on increased and decreased number on $N_{\mathrm{r}}$ in Fig. 7). From Fig. 7 it is evident that there is no such effect on average dispersion value while increasing the number of rings and a limited effect when decreasing to 4 . Figure 8 shows that the bire-

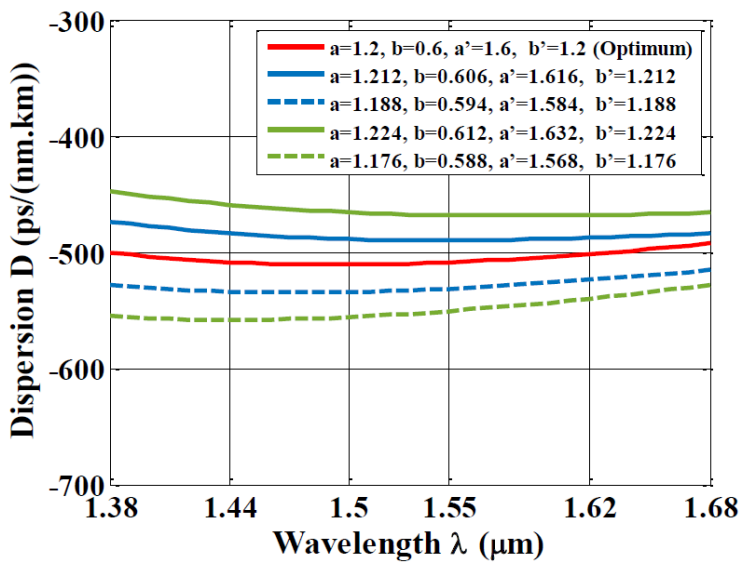

Fig. 6. Dispersion as a function of wavelength for variation of $a, b, a^{\prime}$ and $b^{\prime}$ from $\pm 1 \%$ to $\pm 2 \%$ (units of $a, b, a^{\prime}$ and $b^{\prime}$ are in $\left.\mu \mathrm{m}\right)$.

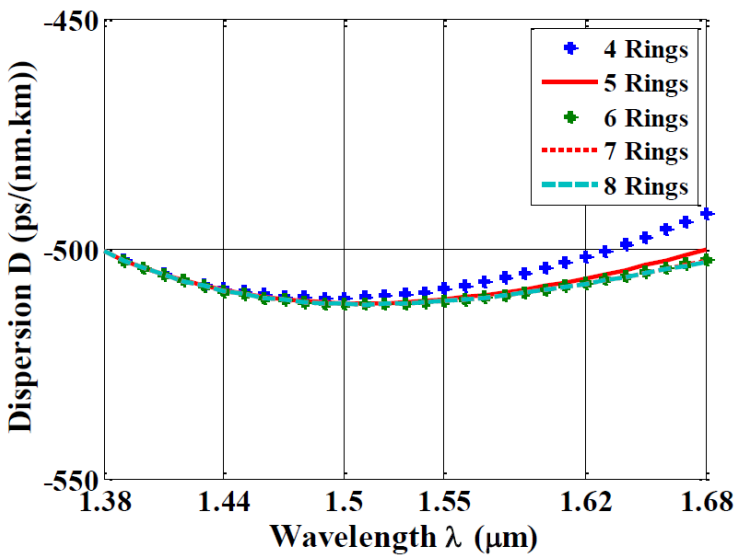

Fig. 7. Dispersion as a function of wavelength for variation of number of rings.

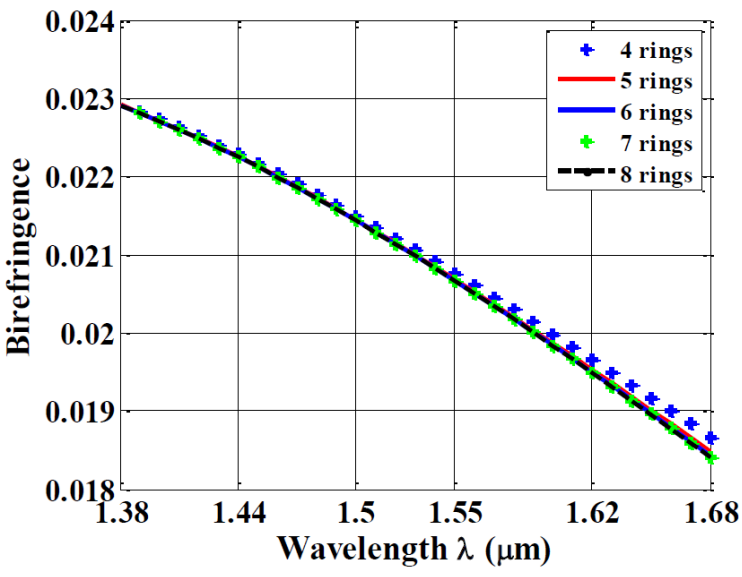

Fig. 8. Birefringence as a function of wavelength for optimum design parameters with variation of number of rings.

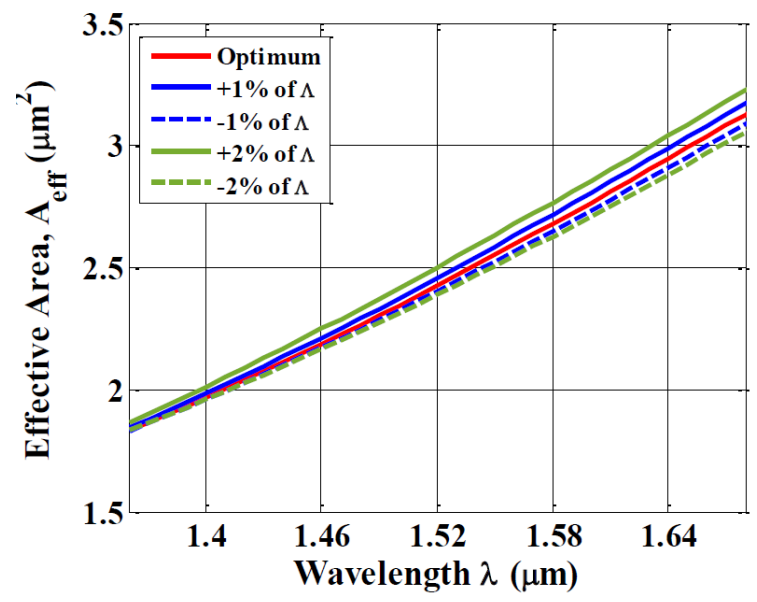

Fig. 9. Effective area as a function of wavelength for optimum design parameters with variation of pitch (A)

fringence of the MO-PCF reaches $2.07 \times 10^{-2}$ at $1.55 \mu \mathrm{m}$ for $N_{\mathrm{r}}=5$. It can be seen that there is no noteworthy influence on birefringence value when we change the number of rings.

Due to the elliptical shape of the center core, the high birefringence of the proposed structure is formed. A fiber of this property can be used to eliminate the effect of polarization mode dispersion (PMD) in transmission systems and many other areas where high birefringence is required. On the other hand, the proposed MO-PCF will be a suitable candidate for applications in optical fiber sensing and polarization maintaining transmission systems as it exhibits high birefringence. Furthermore highly birefringent fibers are extensively used in extremely precise fiber interferometers especially in fiber optic gyroscopes and as a major component for optical fiber sensing applications [22].

One important aspect of the residual dispersion compensating fiber introduces a splice loss, which can be found when coupling between PCFs and conventional SMFs for splice loss is inversely related to effective area and this should be reduced to ensure the optimum performance of the proposed R-DCF. There have been reports of splice- 
free interconnection techniques between PCFs of almost any structure and SMFs, provided the PCF is drawn from individual stackable units as reported by [16]. From Fig. 9 it is seen that the proposed R-DCF exhibits an effective area of about $2.6 \mu \mathrm{m}^{2}$ at wavelength $1550 \mathrm{~nm}$. We have carried out a tolerance analysis of the effective area by varying the pitch size from $\pm 1 \%$ to $\pm 2 \%$, which is shown in Fig. 9. Owing to a small effective mode area; the proposed modified octagonal PCF is expected to be insensitive to bending losses [17].

Fabrication complexity is one of the important challenges in the realization of any proposed PCF. There are several methods, which could be used for fabrication of PCF including the stack and draw method, sol-gel casting, extrusion, ultrasonic drilling etc. Stack and draw method is cost-effective and allows easy control over shape [25]. Several complex PCF designs have been already fabricated by using the stack and draw method, which is explained in detail in [19], [26]. Besides using sol-gel casting technique, many complex structures of PCF have been fabricated by [27]. Sol-gel casting method offers a wide range of design flexibility which is required for dispersion compensation designs [27]. Both stack and draw and sol-gel casting technique are well suited for fabrication of PCF having circular air holes. As our proposed MO-PCF consists of only circular air holes, both methods could be used to fabricate our proposed MO-PCF.

\section{Conclusion}

A new type of modified octagonal PCF with dualelliptical core structure, which can be used as a residual dispersion compensating fiber operating over a $300 \mathrm{~nm}$ bandwidth, has been proposed. The proposed structure exhibits an average dispersion of $-506 \mathrm{ps} /(\mathrm{nm} \cdot \mathrm{km})$ with a variation of $11.3 \mathrm{ps} /(\mathrm{nm} \cdot \mathrm{km})$ in the range from $1380 \mathrm{~nm}$ to $1680 \mathrm{~nm}$. It was shown that the confinement loss of the proposed R-DCF is $0.045 \mathrm{~dB} / \mathrm{km}$ for ten rings. All of these guiding properties make our design a promising costeffective broadband dispersion compensator in WDM optical fiber transmission system while maintaining a single polarization state. In particular, it allows tolerance to fabrication processes when average dispersion and its flatness remain resistant to slight changes of the designed structural parameters during fiber drawing. This fabrication tolerance represents a major advantage of our proposed fiber in contrast to other rather complex PCF structures designed for dispersion compensation [7-9]. Apart from dispersion compensation, this design also maintains single polarization thanks to its high birefringence.

\section{Acknowledgments}

The research is supported by the Ministry of Education Youth and Sports of the Czech Republic, grant
COST LD15803 within the framework of COST Action MP1401, and by the Technology Agency of the Czech Republic, grant TE02000202.

\section{References}

[1] LIU, Y., WANG, J., LI, Y., et al. A novel hybrid photonic crystal dispersion compensating fiber with multiple windows. Optical and Laser Technology, 2012, vol. 44, no. 7, p. 2076-2079. DOI: 10.1016/j.optlastec.2012.03.023

[2] AGRAWAL, G. P. Fiber-Optic Communication Systems. 3rd ed. New York (USA): Wiley, 2002, p. 15-64. ISBN: 0-471-22114-7 (electronic)

[3] GEROME, F., AUGuSte, J. L., BLONDY, J.-M. Design of dispersion-compensating fibers based in a dual-concentric-core photonic crystal fiber. Optics Letters, 2004, vol. 29, no. 23, p. 2725-2727. DOI: 10.1364/OL.29.002725

[4] KOSHIBA, M., SAITOH, K. Structural dependence of effective area and mode field diameter for holey fibers. Optics Express, 2003, vol. 11, no.15, p. 1746-1756. DOI: 10.1364/OE.11.001746

[5] ISLAM, M. A., AHMAD, R., SHARAFAT, M. A., et al. Proposal for highly residual dispersion compensating defected core decagonal photonic crystal fiber over $\mathrm{S}+\mathrm{C}+\mathrm{L}+\mathrm{U}$ wavelength bands. Optical Engineering, 2014, vol. 53, no. 7, 5 p. DOI: 10.1117/1.OE.53.7.076106

[6] FRANCO, M. A. R., SERRÃO, V. A., SIRCILli, F. Microstructured optical fiber for residual dispersion compensation over $\mathrm{S}+\mathrm{C}$ $+\mathrm{L}+\mathrm{U}$ wavelength bands. IEEE Photonics Technology Letters, 2008, vol. 20, no. 9, p. 751-753. DOI: 10.1109/LPT.2008.921085

[7] DA SILVA, J. P., BEZERRA, D. S., ESQUERRE, V. F. R., et al. Ge-doped defect-core microstructured fiber design by genetic algorithm for residual dispersion compensation. IEEE Photonics Technology Letters, 2010, vol. 22, no. 18, p. 1337-1339. DOI: 10.1109/LPT.2010.2055235

[8] ISLAM, M. A., ALAM, M. S. Design of a polarization maintaining equiangular spiral photonic crystal fiber for residual dispersion compensation over $\mathrm{E}+\mathrm{S}+\mathrm{C}+\mathrm{L}+\mathrm{U}$ wavelength bands. IEEE Photonics Technology Letters. 2012, vol. 24, no. 11, p. 930-932. DOI: 10.1109/LPT.2012.2190981

[9] TEE, D. C., BAKAR, M. H. A., TAMCHEK, N., et al. Photonic crystal fiber in photonic crystal fiber for residual dispersion compensation over $\mathrm{E}+\mathrm{S}+\mathrm{C}+\mathrm{L}+\mathrm{U}$ wavelength bands. IEEE Photonics Journal, 2013, vol. 5, no. 3, 7 p. DOI: 10.1109/JPHOT.2013.2265980

[10] HABIB, M. S., AHMAD, R., HABIB, M. S. et al. Residual dispersion compensation over the $\mathrm{S}+\mathrm{C}+\mathrm{L}+\mathrm{U}$ wavelength bands using highly birefringent octagonal photonic crystal fiber. Applied Optics, 2014, vol. 53, no. 14, p. 3057-3062. DOI: 10.1364/AO.53.003057

[11] RAZZAK, S. M. A., Y. NAMIHIRA, Y. Tailoring dispersion and confinement losses of photonic crystal fibers using hybrid cladding. Journal of Lightwave Technology, 2008, vol. 26, no. 13, p. 1909-1914. DOI: $10.1109 /$ JLT.2008.922323

[12] RAZZAK, S. M. A., Y. NAMIHIRA, Y., SABER, A. Y., et al. Dispersion tolerance of various photonic crystal fibers. International Journal of Optomechatronics, 2007, vol. 1, no. 4, p. 359-368. DOI: 10.1080/15599610701672439

[13] RAZZAK, S. M. A., Y. NAMIHIRA, Y. Proposal for highly nonlinear dispersion-flattened octagonal photonic crystal fibers. IEEE Photonics Technology Letters, vol. 20, no. 4, p. 249-251. DOI: 10.1109/LPT.2007.912986 
[14] RENVERSEZ, G., KUHLMEY, B., MCPHEDRAN, R. Dispersion management with microstructured optical fibers: ultraflattened chromatic dispersion with low losses. Optics Letters, 2003, vol. 28, no. 12 , p. 989-991. DOI: 10.1364/OL.28.000989

[15] POLETTI, F., FINAZZI, V., MONRO, T. M., et al. Inverse design and fabrication tolerances of ultra-flattened dispersion holey fibers. Optics Express, 2005, vol. 13, no. 10, p. 3728-3736. DOI: 10.1364/OPEX.13.003728

[16] LEON-SAVAL, S. G., BIRKS, T. A., JOLY, N. Y., et al. Splicefree interfacing of photonic crystal fibers. Optics Letters, 2005, vol. 30, no. 13, p. 1629-1631. DOI: 10.1364/OL.30.001629

[17] ADEMGIL, H., HAXHA, S., ABDELMALEK, F. Highly nonlinear bending insensitive birefringent photonic crystal fibres. Engineering, 2010, vol. 2, no. 8, p. 608-616. DOI: 10.4236/eng.2010.28078

[18] HASAN, M. I., RAZZAK, S. M. A., HABIB, M. S. Design and characterization of highly birefringent residual dispersion compensating photonic crystal fiber. Journal of Lightwave Technology, 2014, vol. 32, no. 23, p. 4578-4584. DOI: 10.1109/JLT.2014.2359138

[19] SUZUKI, K., KUBOTA, H., KAWANISHI, S., et al. Optical properties of a low-loss polarization-maintaining photonic crystal fiber. Optics Express, 2001, vol. 9, no. 13, p. 676-680. DOI: 10.1364/OE.9.000676

[20] KAIJAGE, S. F., NAMIHIRA, Y., HAI, N. H., et al. Broadband dispersion compensating octagonal photonic crystal fiber for optical communication applications. Japanese Journal of Applied Physics, 2009, vol. 48, no. 052401, 8 p.

[21] LI, X., LIU, P., XU, Z., et al. Design of a pentagonal photonic crystal fiber with high birefringence and large flattened negative dispersion. Applied Optics, 2015, vol. 54, no. 24, p. 7350-7357. DOI: $10.1364 / A O .54 .007350$

[22] KIM, S., KEE, C. S., LEE, C. G. Modified rectangular lattice photonic crystal fibers with high birefringence and negative dispersion. Optics Express, 2009, vol. 17, no. 10, p. 7952-7957. DOI: $10.1364 /$ OE.17.007952

[23] STEEL, M. J., WHite, T. P., MARTiJN DE STERKE, C., et al. Symmetry and degeneracy in microstructured optical fibers. Optics Letters, 2001, vol. 26, no. 8, p. 488-490. DOI: 10.1364/OL.26.000488

[24] MAHMUD, R. R., KHAN, M. A. G., RAZZAK, S. M. A. Design and comparison of SF57 over $\mathrm{SiO}_{2}$ on same structured PCF for residual dispersion compensation. Photonics Journal, 2016, vol. 8 , no. 6,10 p. DOI: 10.1109/JPHOT.2016.2628802

[25] GHOSH, D., BOSE, S., ROY, S., et al. Design and fabrication of microstructured optical fibers with optimized core suspension for enhanced supercontinuum generation. Journal of Lightwave Technology, 2015, vol. 33, no. 19, p. 4156-4162. DOI: 10.1109/JLT.2015.2464782

[26] LIU, Z., WU, C., TSE, M. L., et al. Ultrahigh birefringence indexguiding photonic crystal fiber and its application for pressure and temperature discrimination. Optics Letters, 2013, vol. 38, no. 9, p.1385-1387. DOI: 10.1364/OL.38.001385

[27] BISE, R. T., TREVOR, D. J. Sol-gel derived microstructured fiber: fabrication and characterization. In OFC/NFOEC Technical Digest of the Optical Fiber Communication Conference. Anaheim (CA, USA), 2005. DOI: 10.1109/OFC.2005.192772

\section{About the Authors}

Redwan AHMAD was born in Rajshahi, Bangladesh. He received his B.Sc. from Rajshahi University of Engineering and Technology in 2013 and M.Sc from the Czech Technical University in Prague in 2016. He also worked as research assistant in wireless and fiber optics group, Czech Technical University in Prague from 2014 to 2016. Currently he is working as lecturer in the Department of Electrical and Electronic Engineering, World University of Bangladesh. His research interests include super-continuum generation, dispersion compensation, sensing applications etc. using photonic crystal fiber.

Matej KOMANEC is a research assistant at the Faculty of Electrical Engineering, Czech Technical University in Prague. He received his M.S. and Ph.D. degrees in Radio Electronics from the Czech Technical University in Prague in 2009 and 2014, respectively. His current research interests include specialty optical fibers, nonlinear optics, optical interconnects, and fiber sensing. He is a member of OSA, SPIE.

Dmytro SUSLOV is a PhD student at the Faculty of Electrical Engineering, Czech Technical University in Prague. He received his M.S. degree in Radio Electronics from the Czech Technical University in Prague in 2016. His current research interests include specialty optical fibers, nonlinear optics, optical interconnects.

Stanislav ZVANOVEC received his M.Sc. in 2002, and his Ph.D. degree in 2006, both from the Czech Technical University in Prague. Now he is a full professor and deputy-head of the Department of Electromagnetic Field at the Faculty of Electrical Engineering, Czech Technical University in Prague. He leads a free-space and fiber optics team of the Faculty of Electrical Engineering, CTU, and several research projects. His current research interests include wireless optical communications, visible light communications, remote sensing and optical fiber sensors. 